\title{
The Impact of Engagement in Street-based Income Generation Activities on Stimulant Drug Use Cessation among People who Inject Drugs
}

\author{
Lianping $\mathrm{Ti}^{1,2}$, Lindsey Richardson ${ }^{1}$, Kora DeBeck ${ }^{1,3}$, Paul Nguyen ${ }^{1}$, Julio Montaner ${ }^{1,4}$, \\ Evan Wood ${ }^{1,4}$, and Thomas Kerr ${ }^{1,4}$ \\ ${ }^{1}$ British Columbia Centre for Excellence in HIV/AIDS, St. Paul's Hospital, 1081 Burrard Street, \\ Vancouver, BC, Canada V6Z 1Y6 \\ ${ }^{2}$ School of Population and Public Health, University of British Columbia, 2206 East Mall, \\ Vancouver, BC, Canada V6T 1 Z3 \\ ${ }^{3}$ School of Public Policy, Simon Fraser University, 8888 University Drive, Burnaby, BC, Canada \\ V5A 1 S6
}

${ }^{4}$ Department of Medicine, University of British Columbia, 2775 Laurel Street, Vancouver, BC, Canada V5Z $1 \mathrm{M} 9$

\section{Abstract}

Background-Despite the growing prevalence of illicit stimulant drug use internationally, and the widespread involvement of people who inject drugs (IDU) within street-based drug markets, little is known about the impact of different types of street-based income generation activities on the cessation of stimulant use among IDU.

Methods-Data were derived from an open prospective cohort of IDU in Vancouver, Canada. We used Kaplan-Meier methods and Cox proportional hazards regression to examine the effect of different types of street-based income generation activities (e.g., sex work, drug dealing, and scavenging) on time to cessation of stimulant use.

Results-Between December, 2005 and November, 2012, 887 IDU who use stimulant drugs (cocaine, crack cocaine, or crystal methamphetamine) were prospectively followed-up for a median duration of 47 months. In Kaplan-Meier analyses, compared to those who did not engage in street-based income generation activities, participants who reported sex work, drug dealing,

(C) 2014 Elsevier Ireland Ltd. All rights reserved.

Send correspondence to: Thomas Kerr, Director, Urban Health Research Initiative, BC Centre for Excellence in HIV/AIDS, 608 1081 Burrard Street, Vancouver BC V6Z 1Y6,Canada, Tel: 604-806-9116, Fax: 604-806-9044, uhri-tk@cfenet.ubc.ca.

Authors' Contributions: The specific contributions of each author are as follows: LT and TK were responsible for study design; PN conducted the statistical analyses; LT prepared the first draft of the analysis; All authors provided critical comments on the first draft of the manuscript and approved the final version to be submitted.

Conflict of Interest: No conflict declared.

Publisher's Disclaimer: This is a PDF file of an unedited manuscript that has been accepted for publication. As a service to our customers we are providing this early version of the manuscript. The manuscript will undergo copyediting, typesetting, and review of the resulting proof before it is published in its final citable form. Please note that during the production process errors may be discovered which could affect the content, and all legal disclaimers that apply to the journal pertain. 
scavenging, or more than one of these activities were significantly less likely to report stimulant drug use cessation (all $p<0.001$ ). When considered as time-updated variables and adjusted for potential confounders in a multivariable model, each type of street-based income generation activity remained significantly associated with a slower time to stimulant drug cessation (all $p<0.005)$.

Conclusions-Our findings highlight the urgent need for strategies to address stimulant dependence, including novel pharmacotherapies. Also important, structural interventions, such as low-threshold employment opportunities, availability of supportive housing, legal reforms regarding drug use, and evidence-based approaches that reduce harm among IDU are urgently required.

\section{Keywords}

people who inject drugs; stimulants; crack cocaine; crystal methamphetamine; drug cessation; street economy

\section{Introduction}

Stimulant misuse has been associated with various health and social harms, including the transmission of infectious diseases and violence. For instance, syringe sharing, a wellknown risk for HIV transmission, is common among people who inject cocaine and crystal methamphetamine (Fairbairn et al., 2007; Lloyd-Smith et al., 2009; Tyndall et al., 2003). Crack cocaine smoking has also been shown to be an independent risk factor for HIV infection (DeBeck et al., 2009; Edlin et al., 1994; Strathdee and Stockman, 2010). Furthermore, prior studies have demonstrated that the relationship between crack cocaine and sex work increases the likelihood of exploitation and violence among sex workers, including being pressured into unprotected sexual intercourse (Shannon and Csete, 2010; Shannon et al., 2009). There is also a growing body of research that has found an interdependent relationship between crack cocaine markets, drug dealing and violent crimes (e.g., homicide) in North American settings (Baumer et al., 1998; Blumstein and Rosenfeld, 1998).

Many individuals who use illicit drugs engage in various street-based income generating activities to support their ongoing drug use and basic living needs (DeBeck et al., 2007). These activities often include sex work, drug dealing, street-based scavenging and other activities that carry significant risk for severe violence and other health-related harms (Booth et al., 1993; Braitstein et al., 2003; Parker and Bottomley, 1996; Schneider, 2013; Shannon and Csete, 2010). It is well known that illicit drug dependence plays an important role in contributing to an increased reliance on various street-based income generation activities as a means of generating money to buy drugs (Deering et al., 2013; Maher and Curtis, 1992). However, there is also evidence to suggest that some individuals engaged in the street-based economy become increasingly dependent on illicit drugs as a way to cope with the difficulties and demands of their work (Draus et al., 2010; Erickson et al., 2000; Yahne et al., 2002). 
Despite the extensive literature documenting the various harms associated with stimulant drug use among people who inject drugs (IDU) engaged in street-based income generation activities (Baumer et al., 1998; Fairbairn et al., 2008; Maher and Curtis, 1992), and the increasing prevalence of stimulant drug use among these individuals (DeBeck et al., 2011a; Fischer et al., 2006; Werb et al., 2010), the conditions surrounding stimulant drug use cessation are not yet fully understood. Given the growing calls for the identification of social and structural drivers of drug-related harms (Rhodes, 2009, 2002; Strathdee et al., 2010), the present study was conducted to investigate the impact of different types of street-based income generation activities (e.g., sex work, drug dealing, and scavenging) on stimulant drug use cessation in Vancouver, Canada.

\section{Methods}

Data for this study were obtained from the Vancouver Injection Drug Users Study (VIDUS), which is an open prospective cohort that began enrolling IDU through street outreach and self-referral in May, 1996. This study has been described in detail previously (Wood et al., 2001). Briefly, participants are eligible to enroll in the study if they meet the following entry criteria at recruitment: 1) reside in the Greater Vancouver Regional District; 2) have injected illicit drugs in the previous month; and 3) provide written informed consent. At enrollment and on a semi-annual basis, participants complete an interviewer-administered questionnaire and provide a blood sample for serologic testing. Participants received a stipend (\$20 CDN) for each study visit. The study has received ethics approval from St. Paul's Hospital/ University of British Columbia's Research Ethics Board. The present study was conducted between December, 2005 and November, 2012.

For the present analysis, we restricted our sample to participants who reported recent injection or non-injection illicit stimulant drugs (in the last six months) at the time of the baseline interview, and who had at least one subsequent study visit to assess for stimulant drug use cessation. Individuals who initiated stimulant drug use during follow-up were included from the point of initiation of stimulant use and followed forward. Only periods of active use were included in the analyses. Illicit stimulant drugs included: cocaine, crack cocaine, and crystal methamphetamine. Individuals who did not use stimulant drugs at baseline but who initiated stimulant drug use during follow-up were included from the next follow-up interview forward. Consistent with previous analyses focused on the cessation of drug use (DeBeck et al., 2011b), the primary outcome of interest was time to first stimulant drug use cessation during the study period, defined as the first instance of a period of at least six months without any episodes of self-reported stimulant drug use administered by either injection or non-injection. The primary independent variable of interest, engagement in street-based income generation activities, was categorically defined as: 1) none; 2) sex work only; 3) drug dealing only; 4) scavenging only; and 5) engagement in more than one of these activities. 'Sex work' was defined as having exchanged sex for any of the following: money, gifts, food, shelter, clothes, drugs, and favours. 'Drug dealing' was defined as having sold illicit drugs. 'Scavenging' was defined as reporting either recycling (i.e., binning or buying/ selling recycled products), squeegeeing (i.e., washing car windows), or panhandling (i.e., soliciting donations on the street) as a source of income. These activities all referred to the six-month period prior to the follow-up interview and therefore, income generation 
categories are dynamic and can change over time. This categorical variable was measured longitudinally at each follow-up and was included in analyses as a time-updated measure. To estimate the independent relationship between engagement in street-based income generation activities and time to first stimulant drug use cessation, we considered secondary explanatory variables that may potentially confound this relationship. Variables included: age (dichotomized at the median) (Evans et al., 2009); gender (female vs. male; Lejuez et al., 2007); White race (yes vs. no; Falck et al., 2007); year of enrolment (per year increase); HCV serostatus (positive vs. negative); homelessness, defined as living on the street or having no fixed address (yes vs. no; Cox et al., 2014; Mehta et al., 2012); binge drug use, defined as having used injection or non-injection drugs more than usual (yes vs. no; White and Bates, 1995); daily injection or non-injection heroin use (yes vs. no; Werb et al., 2013); daily injection or non-injection prescription opioid use, including Dilaudid (hydromorphone), morphine, oxycodone, illicit methadone (yes vs. no; Evans et al., 2009); incarceration, defined as having been in detention, prison, or jail overnight or longer (yes vs. no; Mehta et al., 2012); drug addiction treatment (detoxification programs and/or behavioural therapies [e.g., a detoxification program, recovery house, residential addiction treatment centre, or engaging with an addiction counselor or participating in peer support programs] vs. methadone maintenance therapy (MMT) vs. both vs. none; DeBeck et al., 2011b; Werb et al., 2013). All non-invariant variables are time-updated and refer to the sixmonth period prior to the follow-up interview unless otherwise indicated.

As an initial step, we compared selected characteristics among participants who reported no engagement in any street-based income generating activity; those who reported one of sex work, drug dealing, or scavenging; and those who reported engaging in more than one of these activities. Using Kaplan-Meier methods, we estimated the cumulative incidence of stimulant drug use cessation separately for each type of street-based income generation activity at baseline. Cumulative incidence of cessation among participants reporting no engagement in street-based income generation activities; those reporting sex work, drug dealing, or scavenging; and those engaging in more than one of these activities were compared using the log-rank test. As a next step, using Cox proportional hazards regression analyses, unadjusted and adjusted hazard ratios were calculated to assess the independent effect of engagement in different types of street-based income generation activities on time to stimulant drug use cessation. To fit the multivariable confounding model, we employed a conservative stepwise variable selection approach (Maldonado and Greenland, 1993). Specifically, we included all variables (where $p<0.05$ in bivariable analyses) in a multivariable model and used a stepwise approach to fit a series of reduced models. After comparing the value of the coefficient associated with the main independent variable of interest in the full model to the value of this coefficient in each of the reduced models, we dropped the secondary covariate associated with the smallest relative change in the main independent variable. We continued this iterative process until the minimum change exceeded 5\%. Remaining variables were included as confounders in our final model. All statistical analyses were performed using SAS software version 9.2 (SAS Institute, Inc., Cary, NC). 


\section{Results}

Of the 887 participants who met the inclusion criteria, 294 (33.1\%) were female and the median age at baseline was 41 years (interquartile range [IQR] $=35-47$ years). Over the study period, the participants contributed 39393 person-months of follow-up, and the median duration of follow-up among the study sample was 47 months (IQR $=19-69$ months). Over the study period, 377 (42.5\%) participants reported a stimulant drug use cessation event. In total, $566(63.8 \%)$ and 810 (91.3\%) reported using injection and noninjection stimulant drugs in the 6 months prior to their baseline interview, respectively. Table 1 provides baseline descriptive characteristics stratified by type of street-based income generation activity. Among the study participants at baseline, 75 (8.5\%) reported sex work only, $201(22.7 \%)$ reported drug dealing only, 152 (17.1\%) reported scavenging only, 136 $(15.3 \%)$ reported more than one of these activities, and 323 (36.4\%) reported none of these activities.

The Kaplan-Meier analysis of time to first stimulant drug use cessation stratified by type of street-based income generation activity at baseline is shown in Figure 1. By the end of the study period, there was a significant difference in cumulative incidence of first stimulant drug cessation among the different types of street-based income generation activities (logrank: $p$ <.001). At four years of follow-up, the cumulative incidence of first stimulant drug cessation was 39.9\% among IDU who reported no engagement in street-based income generation activities (95\% confidence interval [CI]: $34.5-45.8 \%$ ), $26.5 \%$ among those who reported sex work only (95\%CI: $17.1-39.7 \%), 39.7 \%$ among those who reported drug dealing only (95\%CI: $32.6-47.7 \%), 29.9 \%$ among those who reported scavenging only (95\%CI: $22.8-38.5 \%$ ), and $19.4 \%$ among those who were engaged in more than one activity type (95\%CI: $13.2-28.0 \%)$.

The results of the Cox proportional hazards regression analyses examining the associations between the various types of street-based income generation activities and time to first stimulant drug use cessation are shown in Table 2. In multivariable Cox proportional hazards regression analyses, after adjusting for various confounders, engagement in any type of street-based income generation activity remained inversely associated with time to stimulant drug use cessation. Specifically, IDU reporting sex work (adjusted hazard ratio $[\mathrm{AHR}]=0.30 ; 95 \% \mathrm{CI}: 0.14-0.65)$, drug dealing (AHR $=0.32 ; 95 \% \mathrm{CI}: 0.21-0.49)$, scavenging ( $\mathrm{AHR}=0.40 ; 95 \% \mathrm{CI}$ : $0.29-0.56$ ), and engagement in more than one of these activities (AHR $=0.13$; 95\%CI: $0.05-0.33$ ) were all significantly less likely to report stimulant drug use cessation compared to IDU who did not report engaging in any of these activities.

\section{Discussion}

In the present study, we found that a large proportion of IDU in Vancouver reported stimulant drug use cessation during a seven-year period, with $43 \%$ reporting such an event. However, we also found that many IDU (63.6\%) reported engagement in at least one streetbased income generating activity, and when compared to IDU who were not engaged in any street-based income generation activity, those who reported sex work, drug dealing, and/or 
scavenging were significantly less likely to report stimulant drug use cessation. The significantly lower likelihood of stimulant drug use cessation among individuals reporting street-based income generation activity persisted even after adjustment for various confounders, including homelessness and intensity of drug use.

Consistent with previous studies demonstrating a strong association between street-based income generation activities and stimulant drug use (Booth et al., 1993; DeBeck et al., 2011a; Maher and Curtis, 1992), our findings suggest that individuals engaged in these activities were less likely to report cessation from stimulant use. This could be due to the fact that more severe stimulant drug addiction may perpetuate the need to generate income through illegal means. However, it may also be that engagement in the street-based economy itself serves to exacerbate stimulant use through enhanced access to drugs, integration in drug use scenes, or as a result of the stress associated with these activities. Given the growing body of evidence supporting the latter interpretation (Erickson et al., 2000; Kerr et al., 2007), efforts to scale up interventions that address poverty among this population are warranted.

Our findings should be considered alongside the growing body of evidence indicating that drug dependence is a chronic and relapsing condition; thus, cessation is not always sustainable among this population. The present study only explored time to first stimulant drug use cessation, and therefore there is a possibility that the participants may have continued use of other drugs other than stimulants, or relapsed into stimulant use following their first cessation event. It is therefore necessary to further investigate transitions between the use of different illicit drugs as well as sustained drug use cessation among this population. Additionally, it may be important to explore whether the transitions between injection and non-injection routes of administration differ.

It is noteworthy that binge drug use was the strongest factor negatively associated with stimulant drug use cessation among our study sample. This may reflect the additional challenges individuals with higher intensity addiction face in ceasing drug use. Our findings are consistent with a study demonstrating that cocaine "users" report more dependency symptoms, including binge use, compared to "stoppers" (White and Bates, 1995). Other studies conducted on other illicit drugs also present similar findings (Cheng et al., 2010). However, since little is known about binge drug use and its impact on stimulant drug use cessation, future research should seek to explore this relationship further.

Our study also found gender to be a strong predictor of stimulant drug use cessation, with females reporting a longer time to stimulant drug use cessation than males. This finding is inconsistent with previous studies that suggest that males have longer addiction careers than females (Dennis et al., 2005). Past research has also shown that females have higher rates of access to drug addiction treatment compared to males (Wood et al., 2005); however, this finding may be specific to opioid dependence. Given that less is known about stimulant dependence, future research should seek to explore gender-based differences and access to addiction treatment for those dependent on stimulant drugs. 
Our findings have implications for interventions that aim to maximize stimulant drug use cessation among IDU engaged in various street-based income generation activities. An extensive body of research has identified effective substitution therapies for the treatment of some substance use disorders, including opioid and nicotine dependence (Cahill et al., 2012; Comer et al., 2006; Mattick et al., 2009), which have shown to have a positive impact on public health and public order in various settings. For instance, studies have shown that MMT is linked to an increase in formal employment and reduction in engagement in criminal activities (Bell et al., 1992; Corsi et al., 2009; French et al., 1993; Shi et al., 2007), although these positive impacts may be conditioned by the degree to which MMT enrolment and regulation is compatible with mainstream economic activities (Richardson et al., 2012). The present study demonstrated that while detoxification programs and behavioural therapies may be effective in promoting stimulant cessation, MMT did not appear to have the same beneficial impact for stimulant users. Unfortunately, there are currently no proven pharmacotherapies for the treatment of cocaine or crystal methamphetamine addiction so we were unable to assess the impact of these stimulant-specific types of therapies on stimulant dependence. While individual studies have indicated the modest effectiveness of potential medications for the treatment of cocaine dependence (Grabowski et al., 2001; Kampman et al., 2004; Mariani et al., 2012; Shearer et al., 2003), at present, scientific evidence pertaining to pharmacotherapies to treat stimulant drug dependence remains inconclusive given that the majority of studies are limited by high attrition rates and small sample sizes (Castells et al., 2010; Minozzi et al., 2008). Due to the differences in pharmaceutical properties between opioid and stimulant drugs, future randomized controlled trials investigating novel pharmacotherapies for the treatment of stimulant drug dependence should be prioritized. In the meantime, contingency management for stimulant drug cessation may be beneficial, as it has shown some success in studies conducted among MMT patients (Weinstock et al., 2010). Concurrently, prevention efforts that aim to minimize the occurrence of drug use initiation may be an important public health endeavor.

Interventions designed to increase the availability of low-threshold employment opportunities for IDU may reduce engagement in street-based income generation activities that have shown to be associated with stimulant drug use (DeBeck et al., 2011a; Maher and Curtis, 1992). Prior research conducted in Vancouver suggest that if provided with the opportunity, IDU who generate income through sex work and drug dealing were willing to cease these illegal activities and would opt for low-threshold employment opportunities if it were available (DeBeck et al., 2011c). Unfortunately, legitimate and less risky income generation opportunities for IDU remain limited, and a number of barriers to more formal employment among these individuals have been noted in the literature (Braveman et al., 2006; Hoffman, 1997; Richardson et al., 2012, 2010; Rusch et al., 2004).

It is well known that various social, structural, and environmental characteristics operating within the broader risk environment of IDU increase their vulnerability to social instability and poor health (Pauly et al., 2011; Pinkham et al., 2012; Richardson et al., 2013). A large body of evidence has documented links between unstable housing, drug addiction, and risk behaviours (Baumer et al., 1998; Deering et al., 2013; Fairbairn et al., 2007; Maher and Curtis, 1992; Palepu et al., 2010). Given this, as well as findings from the present analysis that point to homelessness as a significant confounder in the relationship between 
engagement in the street-based economy and persistent stimulant use, the provision of supportive housing environments for IDU may also serve to promote disengagement from the street economy and ultimately cessation from stimulant use.

Lastly, research undertaken in North America and elsewhere internationally has documented that prices of illicit drugs remain stable and low even with the roll-out of anti-drug strategies that heavily rely on law enforcement efforts (Office of National Drug Control Policy, 2007; United Nations Office on Drugs and Crime, 2009). Thus, the potential for drug law reform to reduce risky behaviours associated with high intensity addiction should be considered, particularly in settings that criminalize vulnerable drug using populations at significant public health, social, and economic cost. Indeed, reports on the experiences of Portugal's decriminalization efforts suggest that this type of policy reform has potential to reduce drug dependence and crime among this population (Domoslawski, 2011; Kain, 2011). Of particular relevance to the present study, it is likely that illicit drug prices will drop as a result of decriminalization efforts (Bretteville-Jensen, 2006), and thus reduce the need for IDU to engage in various street-based income generation activities as a means of survival.

This study has several limitations. Firstly, VIDUS is not a random sample of IDU and therefore these findings may not be generalizable to other drug using populations. Secondly, many of our measures relied on self-reported information concerning illegal and/or stigmatizing practices and behaviours, including sex work and drug dealing, and are therefore vulnerable to social desirability reporting. This could have resulted in an underreporting of engagement in street-based income generation activities and therefore, estimates of these activities in the present study may have been conservatively reported. Thirdly, as a general limitation of observational studies, the relationship between engagement in streetbased income generation activities and achieving stimulant drug use cessation may be under the influence of unobserved or unmeasured confounding. Future research on street-based income generation activities and stimulant drug use cessation should seek to collect data on a broader range of potential confounders, including mental illness and availability of illicit drugs. Lastly, the covariates were not time lagged in the multivariable Cox regression analyses and therefore we were unable to determine a causal relationship between engagement in street-based income generation activities and stimulant drug use cessation.

In summary, we found an independent association between engagement in different streetbased income generation activities and slower time to stimulant drug use cessation among IDU in Vancouver. Our findings suggest that future research should focus on novel pharmacotherapies for the treatment of stimulant drug dependence. As well, efforts to promote stimulant drug use cessation among IDU should include consideration of the social, structural, and environmental contexts that may be influencing IDUs' engagement in streetbased income generation activities. Accordingly, structural interventions that aim to increase opportunities for low-threshold employment and supportive housing among this population, in addition to legal reforms, are urgently needed in this setting. 


\section{Acknowledgments}

The authors thank the study participants for their contribution to the research, as well as current and past researchers and staff. We would specifically like to thank Deborah Graham, Peter Vann, Jennifer Matthews, Steve Kain, and Tricia Collingham for their research and administrative assistance.

Role of funding: The study was supported by the US National Institutes of Health (R01DA011591). This research was undertaken, in part, thanks to funding from the Canada Research Chairs program through a Tier 1 Canada Research Chair in Inner city Medicine which supports Dr. Evan Wood. Dr. Lindsey Richardson is supported by a Canadian Institutes for Health Research Post-doctoral Fellowship. Dr. Kora DeBeck is supported by a Michael Smith Foundation for Health Research/St. Paul's Hospital Foundation - Providence Health Care Career Scholar Award.

\section{References}

Baumer E, Lauritsen JL, Rosenfeld R, Wright R. The influence of crack cocaine on robbery, burglary, and homicide rates: a cross-city, longitudinal analysis. J Res Crime Delinq. 1998; 35:316-340.

Bell J, Hall W, Byth K. Changes in criminal activity after entering methadone maintenance. Br J Addict. 1992; 87:251-258. [PubMed: 1313321]

Blumstein A, Rosenfeld R. Explaining recent trends in U.S. homicide rates. J Crim Law Criminol. 1998; 88:1175-1216.

Booth RE, Watters JK, Chitwood DD. HIV risk-related sex behaviors among injection drug users, crack smokers, and injection drug users who smoke crack. Am J Public Health. 1993; 83:11441148. [PubMed: 8342724]

Braitstein P, Li K, Tyndall M, Spittal P, O'Shaughnessy M, Schilder A, Johnston C, Hogg R, Schechter M. Sexual violence among a cohort of injection drug users. Soc Sci Med. 2003; 57:561569. [PubMed: 12791497]

Braveman B, Levin M, Kielhofner G, Finlayson M. HIV/AIDS and return to work: a literature review one-decade post-introduction of combination therapy (HAART). Work. 2006; 27:295-303. [PubMed: 17006006]

Bretteville-Jensen AL. To legalize or not to legalize? Economic approaches to the decriminalization of drugs. Subst Use Misuse. 2006; 41:555-565. [PubMed: 16522563]

Cahill K, Stead L, Lancaster T. Nicotine receptor partial agonists for smoking cessation. Cochrane Database Syst Rev. 2012:CD006103. [PubMed: 22513936]

Castells X, Casas M, Pérez-Mañá C, Roncero C, Vidal X, Capellà D. Efficacy of psychostimulant drugs for cocaine dependence. Cochrane Database Syst Rev. 2010:CD007380. [PubMed: 20166094]

Cheng WS, Garfein RS, Semple SJ, Strathdee SA, Zians JK, Patterson TL. Binge use and sex and drug use behaviors among HIV(-), heterosexual methamphetamine users in San Diego. Subst Use Misuse. 2010; 45:116-133. [PubMed: 20025442]

Comer SD, Sullivan MA, Yu E, Rothenberg JL, Kleber HD, Kampman K, Dackis C, O'Brien CP. Injectable, sustained-release naltrexone for the treatment of opioid dependence: a randomized, placebo-controlled trial. Arch Gen Psychiatry. 2006; 63:210-218. [PubMed: 16461865]

Corsi K, Lehman W, Booth R. The effect of methadone maintenance on positive outcomes for opiate injection drug users. J Subst Abuse Treat. 2009; 37:120-126. [PubMed: 19150202]

Cox J, Maurais E, Hu L, Moodie EEM, Law S, Bozinoff N, Potter M, Rollet K, Hull M, Tyndall M, Cooper C, Gill J, Saeed S, Klein MB. The Canadian Co-infection Cohort (CTN 222). Correlates of drug use cessation among participants in the Canadian HIV-HCV Co-infection Cohort. Drug Alcohol Depend. 2014; 137:121-128. [PubMed: 24559606]

DeBeck K, Buxton J, Kerr T, Qi J, Montaner J, Wood E. Public crack cocaine smoking and willingness to use a supervised inhalation facility: implications for street disorder. Subst Abuse Treat Prev Policy. 2011a; 6:4. [PubMed: 21345231]

DeBeck K, Kerr T, Bird L, Zhang R, Marsh D, Tyndall M, Montaner J, Wood E. Injection drug use cessation and use of North America's first medically supervised safer injecting facility. Drug Alcohol Depend. 2011b; 113:172-176. [PubMed: 20800976] 
DeBeck K, Kerr T, Li K, Fischer B, Buxton J, Montaner J, Wood E. Smoking of crack cocaine as a risk factor for HIV infection among people who use injection drugs. CMAJ. 2009; 181:585-589. [PubMed: 19841052]

DeBeck K, Shannon K, Wood E, Li K, Montaner J, Kerr T. Income generating activities of people who inject drugs. Drug Alcohol Depend. 2007; 91:50-56. [PubMed: 17561355]

DeBeck K, Wood E, Qi J, Fu E, McArthur D, Montaner J, Kerr T. Interest in low-threshold employment among people who inject illicit drugs: implications for street disorder. Int J Drug Policy. 2011c; 22:376-384. [PubMed: 21684142]

Deering KN, Lyons T, Feng CX, Nosyk B, Strathdee SA, Montaner JS, Shannon K. Client demands for unsafe sex: the socio-economic risk environment for HIV among street and off-street sex workers. J Acquir Immune Defic Syndr. 2013; 63:522-531. [PubMed: 23614990]

Dennis ML, Scott CK, Funk R, Foss MA. The duration and correlates of addiction and treatment careers. J Subst Abuse Treat. 2005; 28:S51-S62. [PubMed: 15797639]

Domoslawski, A. Drug Policy in Portugal: The Benefits of Decriminalizing Drug Use. Open Society Foundations; Warsaw, Poland: 2011.

Draus PJ, Roddy J, Greenwald M. "I always kept a job": income generation, heroin use and economic uncertainty in 21st century Detroit. J Drug Issues. 2010; 40:841-869.

Edlin BR, Irwin KL, Faruque S, McCoy CB, Word C, Serrano Y, Inciardi JA, Bowser BP, Schilling RF, Holmberg SD. Multicenter Crack Cocaine and HIV Infection Study Team. Intersecting epidemics--crack cocaine use and HIV infection among inner-city young adults. N Engl J Med. 1994; 331:1422-1427. [PubMed: 7969281]

Erickson P, Butters J, McGillicuddy P, Hallgren A. Crack and prostitution: gender, myths, and experiences. J Drug Issues. 2000; 30:767-788.

Evans JL, Hahn JA, Lum PJ, Stein ES, Page K. Predictors of injection drug use cessation and relapse in a prospective cohort of young injection drug users in San Francisco, CA (UFO Study). Drug Alcohol Depend. 2009; 101:152-157. [PubMed: 19181458]

Fairbairn N, Kerr T, Buxton J, Li K, Montaner J, Wood E. Increasing use and associated harms of crystal methamphetamine injection in a Canadian setting. Drug Alcohol Depend. 2007; 88:313316. [PubMed: 17141427]

Fairbairn N, Wood E, Stoltz J, Li K, Montaner J, Kerr T. Crystal methamphetamine use associated with non-fatal overdose among a cohort of injection drug users in Vancouver. Public Health. 2008; 122:70-78. [PubMed: 17645904]

Falck RS, Wang J, Carlson RG. Crack cocaine trajectories among users in a midwestern American city. Addiction. 2007; 102:1421-1431. [PubMed: 17645426]

Fischer B, Rehm J, Patra J, Kalousek K, Haydon E, Tyndall M, El-Guebaly N. Crack across Canada: Comparing crack users and crack non-users in a Canadian multi-city cohort of illicit opioid users. Addiction. 2006; 101:1760-1770. [PubMed: 17156175]

French MT, Zarkin GA, Hubbard RL, Rachal JV. The effects of time in drug abuse treatment and employment on posttreatment drug use and criminal activity. Am J Drug Alcohol Abuse. 1993; 19:19-33. [PubMed: 8382448]

Grabowski J, Rhoades H, Schmitz J, Stotts A, Daruzska LA, Creson D, Moeller FG. Dextroamphetamine for cocaine-dependence treatment: a double-blind randomized clinical trial. J Clin Psychopharmacol. 2001; 21:522-526. [PubMed: 11593078]

Hoffman MA. HIV disease and work: effect on the individual, workplace, and interpersonal contexts. J Vocat Behav. 1997; 51:163-201.

Kain, E. Forbes. URL; 2011. Ten Years After Decriminalization, Drug Abuse Down by Half in Portugal [WWW Document]. http://www.forbes.com/sites/erikkain/2011/07/05/ten-years-afterdecriminalization-drug-abuse-down-by-half-in-portugal/ [accessed 12.3.13]

Kampman KM, Pettinati H, Lynch KG, Dackis C, Sparkman T, Weigley C, O'Brien CP. A pilot trial of topiramate for the treatment of cocaine dependence. Drug Alcohol Depend. 2004; 75:233-240. [PubMed: 15283944]

Kerr T, Kimber J, Rhodes T. Drug use settings: an emerging focus for research and intervention. Int J Drug Policy. 2007; 18:1-4. [PubMed: 17689337] 
Lejuez CW, Bornovalova MA, Reynolds EK, Daughters SB, Curtin JJ. Risk factors in the relationship between gender and crack/cocaine. Exp Clin Psychopharmacol. 2007; 15:165-175. [PubMed: 17469940]

Lloyd-Smith E, Wood E, Li K, Montaner JS, Kerr T. Incidence and determinants of initiation into cocaine injection and correlates of frequent cocaine injectors. Drug Alcohol Depend. 2009; 99:176-182. [PubMed: 18805655]

Maher L, Curtis R. Women on the edge of crime: crack cocaine and the changing contexts of streetlevel sex work in New York City. Crime Law Soc Change. 1992; 18:221-258.

Maldonado G, Greenland S. Simulation study of confounder-selection strategies. Am J Epidemiol. 1993; 138:923-936. [PubMed: 8256780]

Mariani JJ, Pavlicova M, Bisaga A, Nunes EV, Brooks DJ, Levin FR. Extended-release mixed amphetamine salts and topiramate for cocaine dependence: a randomized controlled trial. Biol Psychiatry. 2012; 72:950-956. [PubMed: 22795453]

Mattick R, Breen C, Kimber J, Davoli M. Methadone maintenance therapy versus no opioid replacement therapy for opioid dependence. Cochrane Database System Rev. 2009:CD002209. [PubMed: 19588333]

Mehta SH, Sudarshi D, Srikrishnan AK, Celentano DD, Vasudevan CK, Anand S, Kumar MS, Latkin C, Solomon S, Solomon SS. Factors associated with injection cessation, relapse and initiation in a community-based cohort of injection drug users in Chennai, India. Addiction. 2012; 107:349-358. [PubMed: 21815960]

Minozzi S, Amato L, Davoli M, Farrell M, Lima Reisser AA, Pani PP, Silva de Lima M, Soares B, Vecchi S. Anticonvulsants for cocaine dependence. Cochrane Database Syst Rev. 2008:CD006754. [PubMed: 18425968]

Office of National Drug Control Policy. National Youth Anti-Drug Media Campaign: Campaign Overview 2007. Office of National Drug Control Policy; Washington: 2007.

Palepu A, Marshall B, Lai C, Wood E, Kerr T. Addiction treatment and stable housing among a cohort of injection Drug Users. PLoS One. 2010; 5:e11697. [PubMed: 20657732]

Parker, H.; Bottomley, T. Crack Cocaine and Drugs-Crime Careers. Great Britain Home Office Research Development and Statistics Directorate; London, UK: 1996.

Pauly, B.; Reist, D.; Schactman, C.; Belle-Isle, L. Housing and Harm Reduction: A Policy Framework for Greater Victoria. Centre for Addictions Research of BC; Victoria, BC: 2011.

Pinkham S, Stoicescu C, Myers B. Developing effective health interventions for women who inject drugs: key areas and recommendations for program development and policy. Adv Prev Med. $201210.1155 / 2012 / 269123$

Rhodes T. The "risk environment": a framework for understanding and reducing drug-related harm. Int J Drug Policy. 2002; 13:85-94.

Rhodes T. Risk environments and drug harms: a social science for harm reduction approach. Int J Drug Policy. 2009; 20:193-201. [PubMed: 19147339]

Richardson L, Wood E, Kerr T. The impact of social, structural and physical environmental factors on transitions into employment among people who inject drugs. Soc Sci Med. 2013; 76:126-133. [PubMed: 23157930]

Richardson L, Wood E, Li K, Kerr T. Factors associated with employment among a cohort of injection drug users. Drug Alcohol Rev. 2010; 29:293-300. [PubMed: 20565522]

Richardson L, Wood E, Montaner J, Kerr T. Addiction treatment-related employment barriers: the impact of methadone maintenance. J Subst Abuse Treat. 2012; 43:276-284. [PubMed: 22301085]

Rusch M, Nixon S, Schilder A, Braitstein P, Chan K, Hogg RS. Prevalence of activity limitation among persons living with HIV/AIDS in British Columbia. Can J Public Health. 2004; 95:437440. [PubMed: 15622793]

Schneider S. Violence, organized crime, and illicit drug markets: a Canadian case study. Sociologia, Problemas E Practicas. 2013; 71:125-143.

Shannon K, Csete J. Violence, condom negotiation, and HIV/STI risk among sex workers. JAMA. 2010; 304:573-574. [PubMed: 20682941] 
Shannon K, Strathdee SA, Shoveller J, Rusch M, Kerr T, Tyndall MW. Structural and environmental barriers to condom use negotiation with clients among female sex workers: implications for HIVprevention strategies and policy. Am J Public Health. 2009; 99:659-665. [PubMed: 19197086]

Shearer J, Wodak A, van Beek I, Mattick RP, Lewis J. Pilot randomized double blind placebocontrolled study of dexamphetamine for cocaine dependence. Addiction. 2003; 98:1137-1141. [PubMed: 12873248]

Shi J, Zhao LY, Epstein DH, Zhao C, Shuai Y, Yan B, Jin J, Lu L. The effect of methadone maintenance on illicit opioid use, human immunodeficiency virus and hepatitis $\mathrm{C}$ virus infection, health status, employment, and criminal activity among heroin abusers during 6 months of treatment in China. J Addict Med. 2007; 1:186-190. [PubMed: 21768956]

Strathdee SA, Hallett TB, Bobrova N, Rhodes T, Booth R, Abdool R, Hankins CA. HIV and risk environment for injecting drug users: the past, present, and future. Lancet. 2010; 376:268-284. [PubMed: 20650523]

Strathdee SA, Stockman J. Epidemiology of HIV among injecting and non-injecting drug users: current trends and implications for interventions. Curr HIV/AIDS Rep. 2010; 7:99-106. [PubMed: 20425564]

Swendsen J, Conway KP, Degenhardt L, Glantz M, Jin R, Merikangas KR, Sampson N, Kessler RC. Mental disorders as risk factors for substance use, abuse and dependence: results from the 10-year follow-up of the National Comorbidity Survey. Addiction. 2010; 105:1117-1128. [PubMed: 20331554]

Tyndall M, Currie S, Spittal P, Li K, Wood E, O'Shaughnessy M, Schechter MT. Intensive injection cocaine use as the primary risk factor in the Vancouver HIV-1 epidemic. AIDS. 2003; 17:887893. [PubMed: 12660536]

United Nations Office on Drugs and Crime, 2009. 2009 World Drug Report: Seizures. United Nations Office on Drugs and Crime; Vienna, Austria: 2009.

Volkow ND. Drug abuse and mental illness: progress in understanding Ccmorbidity. Am J Psychiatry. 2001; 158:1181-1183. [PubMed: 11481146]

Weinstock J, Rash CJ, Petry NM. Contingency management for cocaine use in methadone maintenance patients: when does abstinence happen? Psychol Addict Behav. 2010; 24:282-291. [PubMed: 20565154]

Werb D, Adamu T, Buxton J, Shoveller J, Richardson C, Montaner J, Wood E. Patterns of injection drug use cessation during an expansion of syringe exchange services in a Canadian setting. Drug Alcohol Depend. 2013; 132:535-540. [PubMed: 23642315]

Werb D, DeBeck K, Kerr T, Li K, Montaner J, Wood E. Modelling crack cocaine use trends over 10 years in a Canadian setting. Drug Alcohol Rev. 2010; 29:271-277. [PubMed: 20565519]

White HR, Bates ME. Cessation from cocaine use. Addiction. 1995; 90:947-957. [PubMed: 7663316]

Wood E, Li K, Palepu A, Marsh DC, Schechter MT, Hogg RS, G Montaner JS, Kerr T. Sociodemographic disparities in access to addiction treatment among a cohort of vancouver injection drug users. Subst Use Misuse. 2005; 40:1153-1167. [PubMed: 16040375]

Wood E, Tyndall MW, Spittal PM, Li K, Kerr T, Hogg RS, Montaner JS, O'Shaughnessy M, Schechter MT. Unsafe injection practices in a cohort of injection drug users in Vancouver: could safer injecting rooms help? CMAJ. 2001; 165:405-410. [PubMed: 11531048]

Yahne CE, Miller WR, Irvin-Vitela L, Tonigan JS. Magdalena Pilot Project: motivational outreach to substance abusing women street sex workers. J Subst Abuse Treat. 2002; 23:49-53. [PubMed: 12127468] 


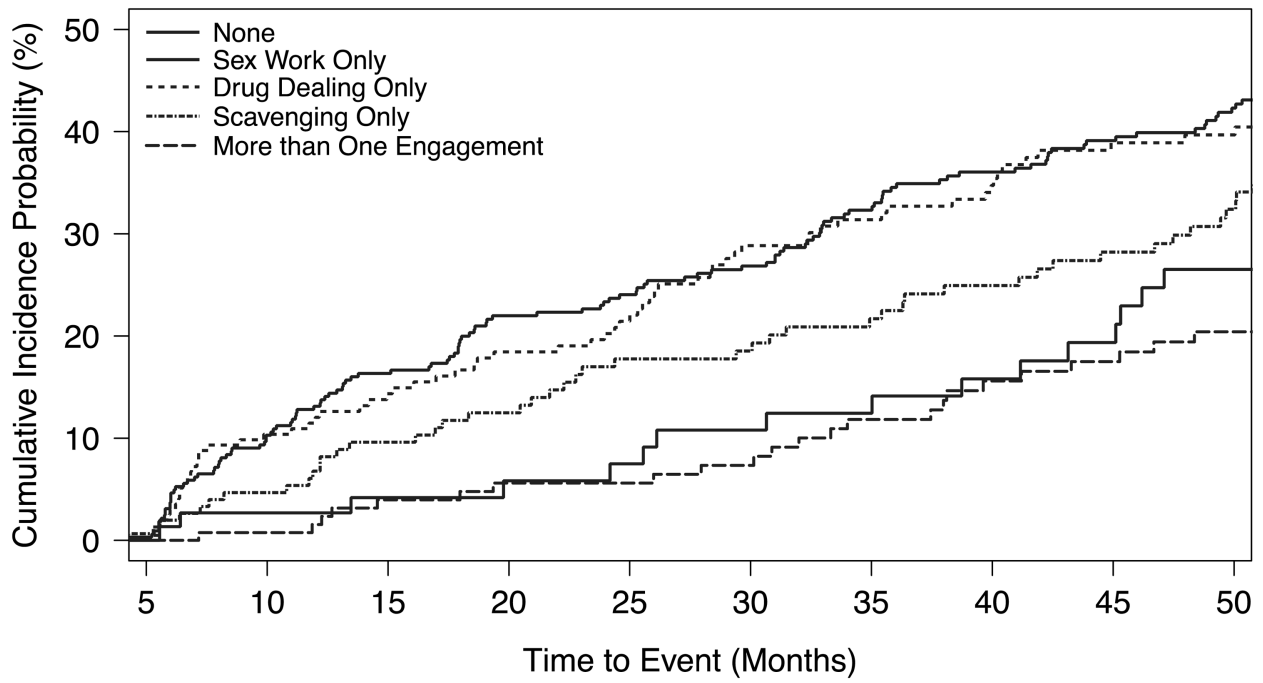

Figure 1.

Kaplan Meier estimates of cumulative incidence of first stimulant drug use cessation among study participants, stratified by type of street-based income generation activity $(n=887)$ 


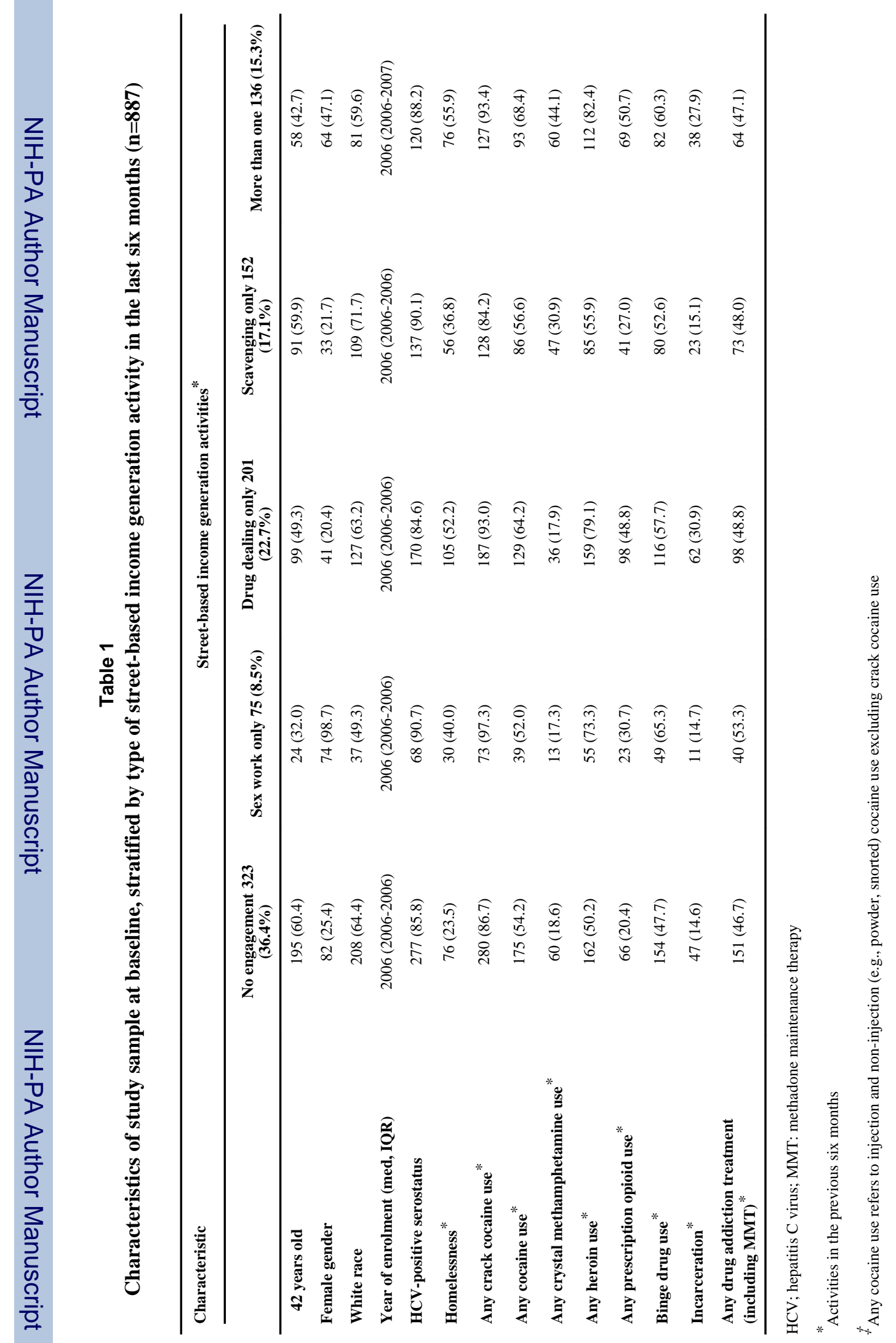


Table 2

Cox proportional hazard analyses of factors associated with time to drug use cessation of stimulant drugs ${ }^{\dagger}$ among study participants $(\mathrm{n}=887)$

\begin{tabular}{|c|c|c|c|c|}
\hline \multirow[b]{2}{*}{ Characteristic } & \multicolumn{2}{|l|}{ Unadjusted } & \multicolumn{2}{|l|}{ Adjusted } \\
\hline & Hazard Ratio (95\% CI) & $p$-value & Hazard Ratio (95\% CI) & $p$-value \\
\hline \multicolumn{5}{|c|}{ Street-based income generation activities ${ }^{*}$} \\
\hline None & Reference & Reference & Reference & Reference \\
\hline Sex work only & $0.16(0.08-0.35)$ & $<0.001$ & $0.32(0.15-0.69)$ & 0.004 \\
\hline Drug dealing only & $0.20(0.13-0.31)$ & $<0.001$ & $0.32(0.21-0.50)$ & $<0.001$ \\
\hline Scavenging only & $0.33(0.24-0.46)$ & $<0.001$ & $0.42(0.30-0.58)$ & $<0.001$ \\
\hline More than one & $0.07(0.02-0.17)$ & $<0.001$ & $0.13(0.05-0.35)$ & $<0.001$ \\
\hline \multicolumn{5}{|l|}{ Age } \\
\hline ( $\geq$ median vs. $<$ median) & $0.94(0.77-1.15)$ & 0.525 & & \\
\hline \multicolumn{5}{|l|}{ Gender } \\
\hline (female vs. male) & $0.65(0.52-0.81)$ & $<0.001$ & $0.76(0.61-0.96)$ & 0.019 \\
\hline \multicolumn{5}{|l|}{ White race } \\
\hline (yes vs. no) & $0.93(0.76-1.14)$ & 0.489 & & \\
\hline \multicolumn{5}{|l|}{ Year of enrolment } \\
\hline (per year increase) & $1.08(0.92-1.27)$ & 0.357 & & \\
\hline \multicolumn{5}{|l|}{ HCV serostatus } \\
\hline (positive vs. negative) & $0.73(0.54-0.98)$ & 0.036 & & \\
\hline \multicolumn{5}{|l|}{ Homelessness * } \\
\hline (yes vs. no) & $0.52(0.40-0.69)$ & $<0.001$ & $0.73(0.56-0.94)$ & 0.017 \\
\hline \multicolumn{5}{|l|}{ Daily heroin use ${ }^{*}$} \\
\hline (yes vs. no) & $0.54(0.40-0.73)$ & $<0.001$ & & \\
\hline \multicolumn{5}{|c|}{ Daily prescription opioid use ${ }^{*}$} \\
\hline (yes vs. no) & $0.74(0.45-1.23)$ & 0.251 & & \\
\hline \multicolumn{5}{|l|}{ Binge drug use ${ }^{*}$} \\
\hline (yes vs. no) & $0.05(0.03-0.08)$ & $<0.001$ & $0.07(0.04-0.11)$ & $<0.001$ \\
\hline \multicolumn{5}{|l|}{ Incarceration * } \\
\hline (yes vs. no) & $0.79(0.58-1.08)$ & 0.141 & & \\
\hline \multicolumn{5}{|c|}{ Drug addiction treatment ${ }^{*}$} \\
\hline None & Reference & Reference & Reference & Reference \\
\hline \multicolumn{5}{|l|}{ Detoxification } \\
\hline $\begin{array}{l}\text { programs/behavioural } \\
\text { therapies }\end{array}$ & $1.86(1.39-2.48)$ & $<0.001$ & $1.55(1.19-2.02)$ & 0.001 \\
\hline MMT & $0.71(0.56-0.91)$ & 0.007 & $0.80(0.63-1.02)$ & 0.071 \\
\hline Both & $1.29(0.93-1.77)$ & 0.124 & $1.20(0.88-1.62)$ & 0.255 \\
\hline
\end{tabular}

CI: confidence interval; $\mathrm{HCV}$; hepatitis $\mathrm{C}$ virus; $\mathrm{MMT}$ : methadone maintenance therapy

*Activities in the previous six months 
${ }^{\dagger}$ Stimulant drugs refer to the following illicit drugs: crack cocaine, cocaine, and crystal methamphetamine 